\title{
The use of the nose to study the inflammatory response of the respiratory tract
}

There are several reasons for investigating inflammatory responses in the nasal mucosa. There is evidence for an increasing frequency of allergic rhinitis, ${ }^{1}$ and nasal symptoms may be an early sign of allergic and occupational airway disease. There is also the possibility that a more general relation between rhinitis and asthma exists. This idea is not novel and at the turn of the century it led to the introduction of different treatments for asthma. ${ }^{2}$ This editorial considers what can be learnt about inflammatory mechanisms by studying the readily accessible human nasal mucosa rather than the relatively inaccessible bronchial mucosa.

\section{Nasal treatments of asthma}

In the latter half of the previous century "the snare, the knife, or caustics" were frequently used to treat chronic catarrhal affections of the upper air tract. ${ }^{3}$ Moreover, asthma was reported to be cured by these radical measures. Francis Rackemann, however, in 1931, in a review ${ }^{4}$ on connections between asthma and the nose, concluded that the widespread attempts to cure asthma by surgically removing foci of infection in the nasal and oral passages were distinctly disappointing. On the other hand, Rackemann also noted that "lesions in the nose and the sinuses are so common in asthma as to be almost a clinical characteristic and they may be of diagnostic importance."

Neural mechanisms have been a basis for connecting nasal and bronchial disease. In 1919 Sluder $^{5}$ described asthma "as a nasal reflex." Dixon and Brodie ${ }^{6}$ had previously shown in dogs that stimulation of the nasal mucosa could produce bronchospasm. One of the treatments that followed was topical cocaine to produce local anaesthesia of the nasal mucosa. (In the 1880 s cocaine had already been used as a mucosal decongestant ${ }^{3}$ in both rhinitis and asthma.) Other nasal treatments in vogue 100 years ago might also have produced anaesthesia or, indeed, required this effect to be endured. Capsaicin, the pungent part of Spanish pepper, is but one example ${ }^{7}$ of a painful local treatment of that time. Capsaicin is now being rediscovered as a nasal drug, but its current praise is based more on interaction with neuropeptides than on clinical efficacy. Nasal anaesthesia has obviously failed as a treatment in both asthma and rhinitis. ${ }^{8}$ Holmberg et $a l^{9}$ have recently shown that topical lignocaine has no effect on allergen induced nasal symptoms. These and other human data on nasal conditions ${ }^{1011}$ currently give little support for the view that axon reflexes and neurogenic inflammation are major components of allergic airway diseases.

Aubier and coworkers ${ }^{12}$ recently reported that bronchial hyperresponsiveness associated with allergic rhinitis is more effectively treated by nasal than by bronchial glucocorticoid administration. In 1984 Henriksen and Wenzel ${ }^{13}$ showed that intranasal glucocorticoid treatment produced significant effects on real asthma and its hyperresponsiveness. In 1988 Reed et al ${ }^{14}$ were surprised to find that intranasal anti-inflammatory treatment prevented seasonal asthma. It seems unfortunate that the value of improving the health of nasal passages in asthma has received so little attention in the last few decades.

\section{Steroids and sympathomimetics}

In 1872 Theodor Weber ${ }^{15}$ presented a "SchwellungTheorie" explaining obstruction in rhinitis and asthma as a vasodilatory phenomenon. Weber thought of asthma as a "bronchial urticaria" and the supportive evidence for his theory rested largely on reactions in the nose. The earliest picture indicating a profuse bronchial mucosal vasculature in asthma may have been drawn by Fraenkel ${ }^{16}$ in 1898, who also observed extensive epithelial desquamation. Even more impressive are the redundant networks of microvessels just beneath the epithelium (which has not been destroyed) of a medium sized asthmatic bronchus depicted by Jeziersky ${ }^{17}$ in 1906 . Jeziersky's beautiful coloured drawings also illustrate a very large sinus vein. In the last few years there has been a renewed interest in vasodilator mechanisms in asthma, due in part to a clear demonstration of large veins in the bronchial wall ${ }^{18}$ if not as abundant as in the nose (fig 1).

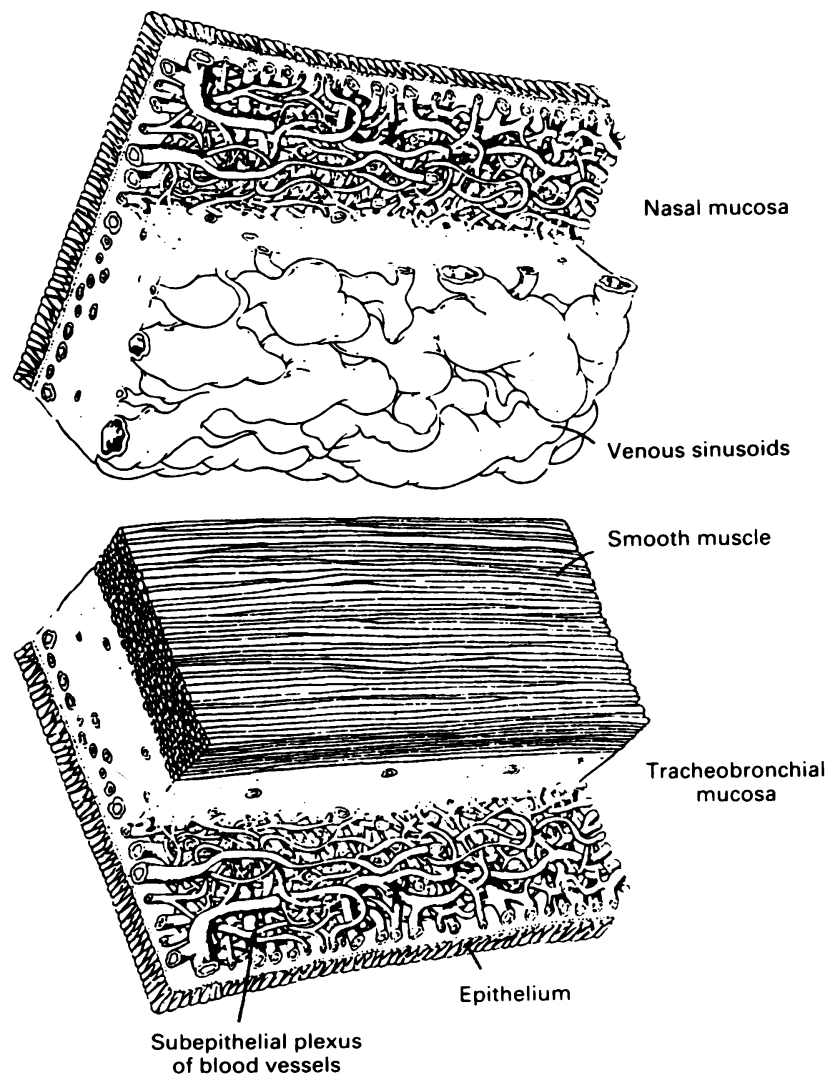

Figure 1 The epithelial lining and the profuse subepithelial microcirculation, two major tissue components in airway inflammation, which may be largely similar in nasal and tracheobronchial airways. $A$ smooth muscle layer corresponding to the bronchial muscle does not exist in the nose, which instead harbours large sinus veins. The latter structures may, less conspicuously, be found also in bronchial tissue (not shown). 
Solis-Cohen suffered from asthma and seasonal rhinitis. He shared the notion that both asthma and rhinitis were characterised by a "vasomotor ataxia of a relaxing variety." $19 \mathrm{He}$ ingested dried bovine adrenals, a material that possessed vasoconstrictor properties. Not only was his own airway disease improved, but his asthmatic patients improved significantly with daily ingestion of this "adrenal substance." 19 The oral efficacy and the slowly developing clinical effect suggest that corticosteroid and not sympathomimetic actions were responsible. ${ }^{2}$

Soon after Solis-Cohen's report purified adrenaline became available. Again, the first known pharmacological action was vasoconstriction. Bullowa and Kaplan, ${ }^{20}$ who discovered the antiasthmatic property of adrenaline injections, concluded that it was vasodilatation and not bronchoconstriction that caused the airflow obstruction in asthma. This view was reversed when adrenaline induced bronchodilatation was demonstrated. ${ }^{8}$ Today still more airway actions of sympathomimetic drugs have been found.

Studies on whole animal models and isolated cells suggest that $\beta_{2}$ agonists may inhibit mast cells, reduce vascular permeability, and attenuate allergen induced airway eosinophilia. ${ }^{21}{ }^{22}$ The response of the nasal mucosa challenged with allergen and inflammatory mediators includes mast cell activation, plasma exudation, eosinophil accumulation and activation, and neural activation. Nasal studies may therefore be helpful in determining whether topical $\beta_{2}$ agonists can inhibit these effects in vivo in human airways, and also whether these drugs may have mucosal effects that are less desirable. Bronchodilator effects clearly cannot be predicted from any nasal experiments. The lack of dilator and constrictor smooth muscle in the nasal mucosa (fig 1), however, may also be considered an experimental advantage. In the nose airway mucosal actions of drugs and mediators can thus be examined in detail and over large dose ranges without the disturbance and the severe limitations that are imposed in the lower airways by effects on bronchial smooth muscle tone.

A continued focus on the nose has been helpful in delineating airway anti-inflammatory actions of glucocorticoid drugs. When adrenocorticotrophic hormone and cortisone became available, ear, nose, and throat and pulmonary specialists in Johns Hopkins Hospital in Baltimore were the first to examine the effects of these agents in severe asthma. ${ }^{23}$ Dramatic improvements were recorded. Furthermore, the careful inspections of the nose performed by these workers showed that the mucosal exudations and secretions and the eosinophilia disappeared.

\section{Eosinophils, mast cells, and the epithelium}

Some of the reports on the pathology of asthma in the early 1900 s are based on examinations of the entire respiratory tract in patients who never received disease modifying antiinflammatory treatment. Despite the importance of many of these studies (two have already been mentioned ${ }^{16}{ }^{17}$ ) they cannot be traced easily in currently available publications. In 1916 Felix Marchand ${ }^{24}$ reported on the presence of eosinophils, mast cells, and other cells in the nasal and bronchial mucosa of patients who had died from asthma. Eosinophils were abundant both in the epithelium and in other parts of the nasal and bronchial airways, and sometimes also in the muscle and the peribronchium. He found leucocytes attached to fibrin threads in the sputum, and even found eosinophils in samples of asthmatic sputum that had been well preserved since 1854. Marchand noted that eosinophils and Charcot crystals could be selectively present where epithelial desquamation occurred. He disagreed, however, with his colleague Fraenkel, who was the first champion of the view that epithelial desquamation is a unifying characteristic of asthmatic airways. ${ }^{16}$ As shown by Marchand and many other pathologists in 1900-40, the bronchial epithelial lining may be well preserved even in subjects who have died from asthma.

From his observations Marchand formed conclusions about local differentiation and turnover of eosinophils in nasal and bronchial airways. He noted that plasma cells and mast cells often occurred with eosinophils but he could not find transitional forms between these types of cell. He saw that the most superficial mast cells had a reduced granularity and that goblet cells were abundant.

In a second study of the pathology of asthma Marchand ${ }^{25}$ again found intriguing similarities between nasal, tracheal, and bronchial changes. He noted the abundance of microvessels in the airway mucosa and carefully described the widespread eosinophilia. He remarked on the accumulation of lymphocytes and the increased occurrence of goblet cells. He pioneered the tantalising thought that the epithelium may have a primary role in asthma by releasing chemotactic and inflammatory factors that will affect the subepithelial microcirculation and other airway targets. He also provided evidence that even the severest form of asthma may not be associated with pathological alterations in the lung tissue, including the alveolar lining.

Marchand made important observations on the cellular pathology of the airways in asthma and firmly attested to the inflammatory nature of this disease, which he called chronic eosinophilic bronchitis. (He did not include "desquamative" for the reasons given above.) In fact, he criticised the treatment for not being anti-inflammatory, and he criticised the experimental asthma models for not being similar to the real disease because they lacked its inflammatory nature. Furthermore, Marchand put forward the view that the pathological features of the nasal and the tracheobronchial mucosa may agree in many respects in this disease. This observation was confirmed in 1928 by two North American pathologists, ${ }^{26}$ who reported "an essential similarity [in severe asthma] between the changes in the nasal mucous membrane and those of the epithelial and subepithelial layers of the bronchi," though those authors considered this an original discovery.

In recent years eosinophils and mast cells have been studied frequently in allergic airway disease. Techniques such as the rhinobrush for obtaining inflammatory cells from the nose showed that mucosal eosinophils are considerably increased within two hours of exposure to allergen, ${ }^{27}$ and a similar rapid increment of eosinophils was recorded after topical nasal application of platelet activating factor acether. ${ }^{28}$ During natural exposure to allergen the mucosal eosinophils accumulate early in the season and are increased throughout and beyond the period of exposure..$^{29} 30$ This response is associated with an increase in eosinophil derived toxic proteins on the mucosal surface ${ }^{3031}$ (examined by analyses of lavage fluid obtained daily during the season). Interestingly, eosinophils and eosinophil derived proteins are increased in seasons in which allergen exposure is mild and that the early changes in eosinophil responses are prevented by topical glucocorticoid treatment. ${ }^{30}$ More limited time point studies, carried out in the lower airways, suggest that these effects may also occur in the bronchial mucosa in asthma. ${ }^{32} \mathrm{~A}$ recent study of the immunohistology of the nasal mucosa ${ }^{33}$ has advanced the view that activated $\mathrm{T}$ cells (CD4 $\mathrm{T}$ lymphocytes) may govern the mucosal eosinophilia in allergic airway disease.

The observation that prolonged treatment with topical steroids inhibits not only the allergen induced late phase response but also the early phase symptoms was first made in rhinitis $^{34}$ and later in asthma. ${ }^{35}$ Pipkorn and his colleagues showed both the clinical efficacy of topical glucocorticoids and their effect on immediate and late 
allergen induced mediator release in allergic rhinitis. ${ }^{36-38}$ Their finding of in vivo inhibition of mast cell mediator release provided a scientific rationale for starting topical corticosteroid treatment before the expected onset of the allergic season. Allergen induced late phase responses in the nose and the associated increased nasal responsiveness were also inhibited by topical glucocorticoid pretreatment. ${ }^{37} 38$ Enerbäck subdivided mast cells into connective tissue mast cells and mucosal mast cells. ${ }^{39}$ By a newly developed imprint technique ${ }^{40}$ and by biopsies ${ }^{41}$ these workers showed that during natural seasonal exposure mucosal mast cells migrated from the connective tissue stroma into the epithelium, where many appear as degranulated cells. By their close connection wi i the superficial microcirculation mast cell mediators may play a part in the plasma exudation response in seasonal rhinitis. ${ }^{3142}$ Antihistamines are now widely used in allergic rhinitis. These drugs have been effective in several acute allergen challenge studies in rhinitis and asthma ${ }^{434}$ but the efficacy may be reduced in more chronic conditions. ${ }^{44}$ Surprisingly, it still remains to be investigated whether these drugs affect inflammatory indices of the airway mucosa in disease, such as during exposure to seasonal allergens.

\section{Other cellular changes}

Allergen challenges in allergic rhinitis and asthma cause mast cell tryptase release in the nose and the bronchi respectively. ${ }^{45-47}$ Mast cells, like lymphocytes, eosinophils, and many other migrating and structural cells in the airway, have the capacity to produce and release different mediators and enzymes as well as a range of cytokines, ${ }^{489}$ which are potentially important in chronic inflammation (fig 2). Because of their strategic position it is of particular interest that the epithelial lining cells may produce both mediators and cytokines. Data obtained in studies of in vitro cultures of human upper and lower airway epithelial cells show similarities in this respect-for example, concerning the capacity for interleukins (IL-1, IL-6) and granulocyte-monocyte colony stimulating factor (GMCSF) production. ${ }^{5051} \mathrm{GM}-\mathrm{CSF}$ may increase eosinophil survival and its production is inhibited by corticosteroids. ${ }^{5051}$ Other structural cells, such as fibroblasts, also express the genes for IL-6, IL-8, and GM-CSF and this may occur at a higher rate in cells derived from chronically inflamed nasal tissue than in normal control cells. ${ }^{49}$ The stimulus for epithelial and fibroblast cytokine production may be IL-1 and tumour necrosis factor (TNF), derived from monocytes or another source. In vitro observations thus suggest that epithelial cells and fibroblasts may compete with mast cells, eosinophils, and lymphocytes for regulatory roles in chronic airway inflammation.

Less is known about the source, the release, and the role in vivo of cytokines. Notably, in vivo administration of select cytokines has resulted in effects differing from those seen in vitro. For example, IL-8, which is proinflammatory in many in vitro systems, has pronounced anti-inflammatory effects in in vivo studies. ${ }^{52} \mathrm{~A}$ range of interleukins may appear on the nasal and bronchial mucosal surface after allergen challenge, but in allergic asthma and rhinitis many inflammatory cytokines have yet to be identified. In rhinovirus infection increased concentrations of interferons, ${ }^{53}$ including $\gamma$ interferon, ${ }^{54}$ have been observed. We also need to learn more about the presence and roles of macromolecules of the extracellular matrix. Collagens, fibrin-fibronectin gels, and hyaluronan may provide cell adhesion and migration sites, be a source of inflammatory mediators, and have other functions besides their roles in tissue repair and growth. ${ }^{55}$

Much of the current research in rhinitis and asthma is focused on cellular changes in biopsy material and lavage fluid. These materials are analysed by molecular biology techniques and are well suited for showing similarities between the nasal and the bronchial mucosa. Thus mucosal expression of leucocyte endothelial adhesion molecules of potential importance in airway eosinophilia may be increased in asthma and rhinitis. ${ }^{5657}$ Subjects with atopic rhinitis and atopic asthma respectively also have more nasal and bronchial mucosal cells with positive hybridisation signals for TNF $\alpha$ mRNA than do normal volunteers. ${ }^{58}$ In allergic rhinitis and asthma the airway mucosa appears to have a well developed capacity for antigen presentation. Thus Langerhans cells are present in the nasal mucosa. They increase after allergen exposure and this is inhibited by glucocorticoids. ${ }^{59}$ Many types of cells besides Langerhans' cells express class II major histocompatibility complex antigens and may act as antigen presenting cells. These cells include dendritic cells, monocytes/macrophages, B cells, and epithelial cells. ${ }^{6061}$ Nasal mucosal biopsy specimens obtained from adults with asthma have lymphocytes and macrophages that are pathologically similar to those found in the bronchial mucosa and it has been suggested that nasal biopsy might be useful in assessment of asthma. ${ }^{62}$ In children aged 1-9 months nasopharyngeal smears containing eosinophils and eosinophil derived proteins are considered by some to be a sign of asthma. ${ }^{63}$ The possibility that nasal lavage and biopsy data may be of diagnostic help in asthma is intriguing but largely unexplored. Safe nasal challenges and examination of inflammatory mucosal indices should be useful in studies of occupational asthma, which often is preceded by or associated with "occupational rhinitis." 6465

\section{What is airway inflammation?}

Much of the functional evidence for inflammation in asthma and rhinitis, in their mildest to their severest forms, emanate from the clinical efficacy of glucocorticoids. Glucocorticoids, however, are exceedingly complex pharmacologically, making it difficult to decide which actions are clinically important. It is also clear that glucocorticoids are not active against all types of airway inflammation. Hence nasal inflammation and bronchial inflammation are not well defined by reference to the effect of glucocorticoid drugs. Traditionally, inflammation is equated with the presence of inflammatory cells. The cell studies, which now include detailed analyses of the capacity of airway lymphocytes, monocytes, mast cells, and eosinophils, may show that the airway is "immunocompetent" and may show which mechanisms are fuelling inflammatory processes. What is little discussed, however, is the possibility that the presence of these cells may also reflect postinflammatory conditions or unknown, even trivial, processes. The cells may further participate in successful repair or defence reactions that occur with little help from the airway end organs. The cell data alone may therefore not be adequate to identify inflammation. Indices of airway tissue responses are also needed and may provide crucial information about the occurrence of airway inflammation.

\section{Inflammatory tissue responses}

The classical signs of rubor, dolor, calor, tumour, and functio laesa are unhelpful as they are not specific to inflammation. Rubor often reflects an irritant induced increase in blood flow with no inflammation present. Pain and heat are not characteristic features of allergic airways. Tumour is important, but is the swelling due to oedema, intravascular pooling of blood, bronchoconstriction, cell accumulation, tissue growth, or other factors? Current 


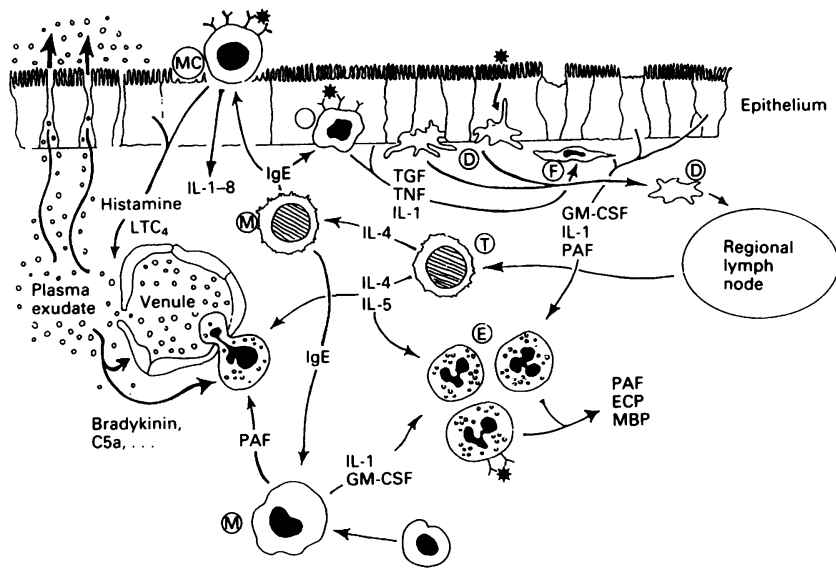

Figure 2 Diagram depicting part of the immunocompetence (allergen presentation by dendritic cells $(D)$, and activated lymphocytes, $T$ and $B$ ) and part of the inflammatory potential of the mucosa (as reflected by accumulation, priming, and activation of inflammatory trafficking and structural cells). When significant inflammatory processes occur, whether driven by immune or other mechanisms, end organ lesions are evident as mucosal exudation of plasma. Plasma exudates, trafficking cells (mast cells (MC), monocytes and macrophages (M), eosinophils $(E))$, structural cells (epithelium, endothelium, fibroblasts $(F)$, and extracellular matrix macromolecules (not drawn) contribute mediators for perpetuation of the mucosal inflammation. IL-1-8-interleukins 1-8; LTC-leukotriene C; C5a-complement 5a; GM-CSF-granulocytemacrophage colony stimulating factor; $P A F$ - platelet activating factor; $E C P$ - eosinophilic cationic; $M B P$-major basic protein, $T G F$-tumour growth factor; TNF-tumour necrosis factor.

techniques allow further quantitative measurements of nasal and bronchial mucosal blood flow, secretion, and mucociliary transport. Effects on these variables are also important but perhaps occur spontaneously or are induced by neural irritants more often than they are caused by inflammation. Finally, poor function may be a misleading term.

In a series of studies we have compared inflammatory responses in human nasal and guinea pig tracheobronchial airways. Our findings suggest the possibility that mucosal exudation of plasma may well reflect ongoing airway inflammation ${ }^{66}$ (figs 2 and 3). Plasma extravasation from the profuse subepithelial microcirculation and the subsequent exudation of plasma across the mucosa into the lumen is not just an exaggeration of the normal baseline exchange of fluid and solutes between the capillary circulation and the mucosa. ${ }^{47-69}$ The response includes participation by the postcapillary venules as a specific end organ, and the permeability of the venules is selectively increased by inflammatory factors and mediators. In guinea pig airways

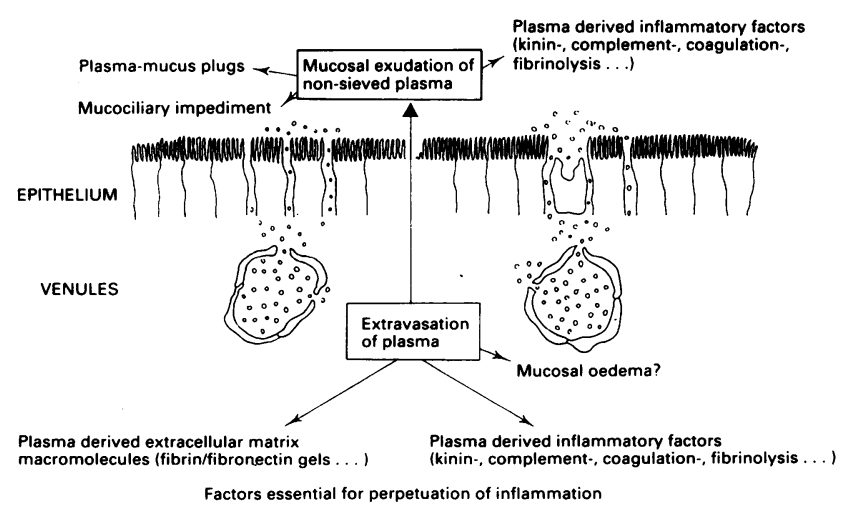

Figure 3 Some of the potential pathophysiological roles of plasma exudation in nasal and tracheobronchial airways. An additional role concerns the usefulness of plasma exudation indices on the mucosal surface for monitoring the intensity of the subepithelial inflammatory process. plasma exudation is readily induced by "non-inflammatory" factors that merely evoke a neural response ${ }^{67}$ as well as by immune mediated mechanisms. In the human airways, however, irritant induced neural actions that increase blood flow and secretion, induce sneezing, and even cause pain do not produce any mucosal exudation of plasma. ${ }^{11}$ Plasma exudation thus seems to be a specific inflammatory response in human airways. It is also a general response in the sense that it occurs regardless of which cellular or non-cellular mechanism drives the inflammation. Hence mucosal exudation of plasma reflects equally the inflammatory airway response in allergy and in infection. A plasma exudate not only is a measure of the intensity of inflammation but also contributes to the vicious circles and sequelae of airway inflammation (fig 3 ).

The airway mucosal surface appears to be the main destination of the plasma exudate that is produced by mucosal challenges. ${ }^{7071}$ Exudative indices analysed in mucosal surface liquids may thus promptly and quantitatively reflect subepithelial inflammatory processes. ${ }^{667}$ Such agreement between mucosal surface and subepithelium may not be valid for the cellular indices of inflammation. As observed in both allergic rhinitis and asthma, the efficacy of glucocorticoid treatment may be assessed by monitoring exudative indices in airway discharges. ${ }^{7073}$ Effective $^{72}$ topical glucocorticoid treatment also prevents the appearance of plasma derived mediators, such as bradykinin, on the mucosal surface. ${ }^{72}$ Work on the human nose suggests that topical glucocorticoids may not produce appreciable vasoconstriction, ${ }^{74}$ nor may they produce direct venular antipermeability effects in the airways. ${ }^{75}$ Moreover, agents that produce significant vasoconstriction such as topical oximetazolin (an $\alpha$ adrenoceptor agonist) may not affect the mucosal exudation process, ${ }^{76}$ probably because the profuse subepithelial microcirculation provides the mucosa with a surplus of blood. The antiexudative effects of topical airway glucocorticoids therefore reflectanti-inflammatory rather than simple vascular effects. Corticosteroids have many actions, and the exact mechanisms that are crucial to their anti-inflammatory and antiexudative effect remain speculative.

The idea that plasma extravasation is a specific and unifying characteristic of tissue inflammation originated with the astute observations of Virchow's pupil Cohnheim. ${ }^{77} \mathrm{He}$ also noted that the extravasation of leucocytes was a distinctly different phenomenon, though it frequently occurred in inflammation and took place across the same microvessels that exuded the plasma.

\section{Airway inflammation is not pulmonary \\ inflammation}

The airway mucosa receives systemic arterial blood and the airway microvessels respond with plasma exudation to many inflammatory stimuli that may not affect the pulmonary circulation. On the other hand, pulmonary inflammation may be produced by distinct pulmonary microvascular-alveolar mechanisms that may not apply to the airway microcirculation and epithelium. ${ }^{78}$ It should therefore not be surprising to find that mucosal inflammatory responses in the tracheobronchial airways agree better with nasal mucosal responses than with responses occurring in the terminal airways and parenchymal region. This consideration may be important. For example, bronchoalveolar lavage harvests material emanating largely from alveoli, not thought to be directly affected in the pathophysiology of asthma. Although successful attempts have been made at carrying out bronchus specific lavage in asthma ${ }^{79}$ the likelihood of recovering fluid that reflects alveolar as well as bronchial surface liquids is a potential 
drawback. ${ }^{80}$ It is also a concern that the recovered lavage fluid contains material that has accumulated on the bronchoalveolar surface for an unknown period. In contrast, nasal lavage techniques (see below) are airway specific and fixed periods can easily be achieved. The nasal responses may reflect tracheobronchial responses better than do pulmonary inflammatory responses as shown by lavage material.

\section{Plasma exudation may not produce oedema} Apart from the neurogenic aspect, plasma exudation responses are similar in the animal tracheobronchial and the human nasal airways. Similar effects are seen in response to challenge with allergen and various mediators (such as histamine, bradykinin, and leukotriene $\mathrm{D}_{4}$ ). The nature of the process is also similar. ${ }^{6677181-84}$ For example, the mucosal exudation of plasma solutes is not size selective. A large protein such as fibrinogen may therefore reflect the exudation better than albumin, which enters the airway lumen more easily under baseline conditions. The observation of bulk, non-sieved exudation first in animal airways and then in the human nose helped us to design a study where allergen induced immediate plasma exudation was seen in asthmatic bronchi. Within five minutes of challenge fibrinogen concentrations in bronchial lavage liquids were increased almost 10 fold. ${ }^{47}$ The entry of plasma exudates into the airway lumen apparently occurs with great ease in human airways with intact epithelial linings. ${ }^{4783}$ These observations agree with results of work in animals showing that mucosal stimulus induced extravasation of plasma may not produce airway oedema. ${ }^{85}$ Hence mucosal exudation of plasma may not reflect the presence of extensive saturated mucosal oedema. It should be viewed, we think, rather as a mechanism that prevents oedema formation. The quantitative evidence for actual airway oedema in asthma and rhinitis is not strong. In contrast, the presence of plasma proteins in the lumen has been well documented in these diseases. Mucosal thickening may still be important because more cells, blood vessels, extracellular matrix, etc, are present.

\section{Mucosal exudation without epithelial damage and without increased absorption}

The lack of size selectivity for the entry of plasma proteins into the airway lumen must reflect a high permeability of the epithelial lining. Yet the exudative flux of plasma across the mucosa is not associated with an increased absorption ability. ${ }^{82-84} \mathrm{~A}$ very slight increase in subepithelial hydrostatic pressure, produced by the exudate itself, appears sufficient to open valve like gates between epithelial cells. ${ }^{86}$ Thus plasma solutes enter the airway lumen without increasing the capacity for mucosal absorption. This separation between exudation and absorption "permeabilities" of the epithelium has been discovered in animal tracheobronchial airways and confirmed by data on the human nose. It may also characterise the human tracheobronchial mucosa. The epithelial tight junctions appear to be dynamic structures, which readily and reversibly yield to the plasma that moves towards the mucosal surface. ${ }^{66}$ This notion has called for a redefinition of the previously proposed ${ }^{88}$ role of plasma exudation in respiratory defence $e^{6671}$ and in the pathogenesis of airway diseases $^{66}$ (fig 3 ).

The presence of plasma proteins in rhinitic and asthmatic airways cannot be considered evidence of a general hyperpermeability of the epithelial lining, though this has been a popular belief. Similarly, we may no longer say that luminal plasma proteins reflect airway epithelial damage and disruption. The denudation of the airway epithelium in asthma is now supported by data from biopsy material but artefactual changes associated with the biopsy may have played a part. ${ }^{89-91}$ Nasal biopsy and functional data suggest that longstanding allergic inflammation may not be associated with epithelial damage. Indeed, the airway epithelial lining becomes tighter rather than more permeable during the birch pollen season..$^{92}$ Increased epithelium tightness has thus been observed in an exudative airway disease where the mucosa has been endowed with activated eosinophils for several weeks. ${ }^{30} 92$

Studies on the absorption ability of the airway mucosa cannot have the same specificity in the bronchi as in the nose. A careful investigation by Elwood et al,,$^{93}$ however, indicated that bronchial absorption may not be increased in asthma or bronchial hyperresponsiveness. Whereas these observations agree with data on the integrity of the epithelial barrier in rhinitis they are at variance with the generally adopted notion that epithelial damage and denudation are characteristics of asthma.

\section{Mucosal hyperresponsiveness}

In asthma the techniques of standardised challenge and spirometry are used to identify airway hyperresponsiveness. The precise quantitative definition of what constitutes bronchial hyperresponsiveness in clinical tests ${ }^{94}$ is not matched by a precise knowledge of which factors are contributing to this phenomenon. The response of the lungs to histamine, methacholine, and other challenges thus reflects a "black box" of airway hyperresponsiveness. Furthermore, increased responsiveness may not always identify asthma or even inflammation in asthma. ${ }^{95}$ Altered responsiveness of the end organs of the mucosa may be induced by inflammatory processes in the airways, and such functional alterations in the mucosa may prove to be important characteristics of asthma and rhinitis. As the nose lacks smooth muscle, histamine and methacholine challenges provide an opportunity to examine the specific end organ reactivity of the airway mucosa. Histamine (as well as bradykinin and $\mathrm{LTD}_{4}$ ) can selectively assess the exudative responsiveness of the mucosal microcirculation. ${ }^{8196}$ Methacholine is without exudative effects ${ }^{6797}$ and may be used to assess the secretory responsiveness of the airway mucosa. Hyperresponsiveness of the sensory nerves can be detected by nasal challenges with capsaicin or nicotine. ${ }^{109}$ The tissue responses to these neurogenic stimuli include increases in secretion ${ }^{98}$ and blood flow (in human airways the neural stimulation does not produce plasma exudation ${ }^{10}{ }^{11}$ ). Thus measurement of secretory indices such as fucose secretion appears to be suitable for determining the sensory responsiveness of the nasal airway to capsaicin and nicotine. ${ }^{10}$ The sneeze or cough response to challenge may be abolished by drugs quite distinct from those that affect the neurogenic tissue responses and must therefore be considered separately. ${ }^{99100}$ We can also examine the "responsiveness" of the barrier function of the epithelial lining. Thus the potency of $\mathrm{H}_{2} \mathrm{O}_{2}$ or other membrane active agents in increasing airway absorption may provide useful information abut the fragility of the epithelial junction. The end organ responses may be direct or linked to increased mucosal "releasability" of mediators, enzymes, and cytokines. The number of different facets of end organ responsiveness and mediator releasability that can be examined in vivo in the nasal mucosa is now limited only by the availability of specific and well validated challenge agents and, equally, methods of analyses. 


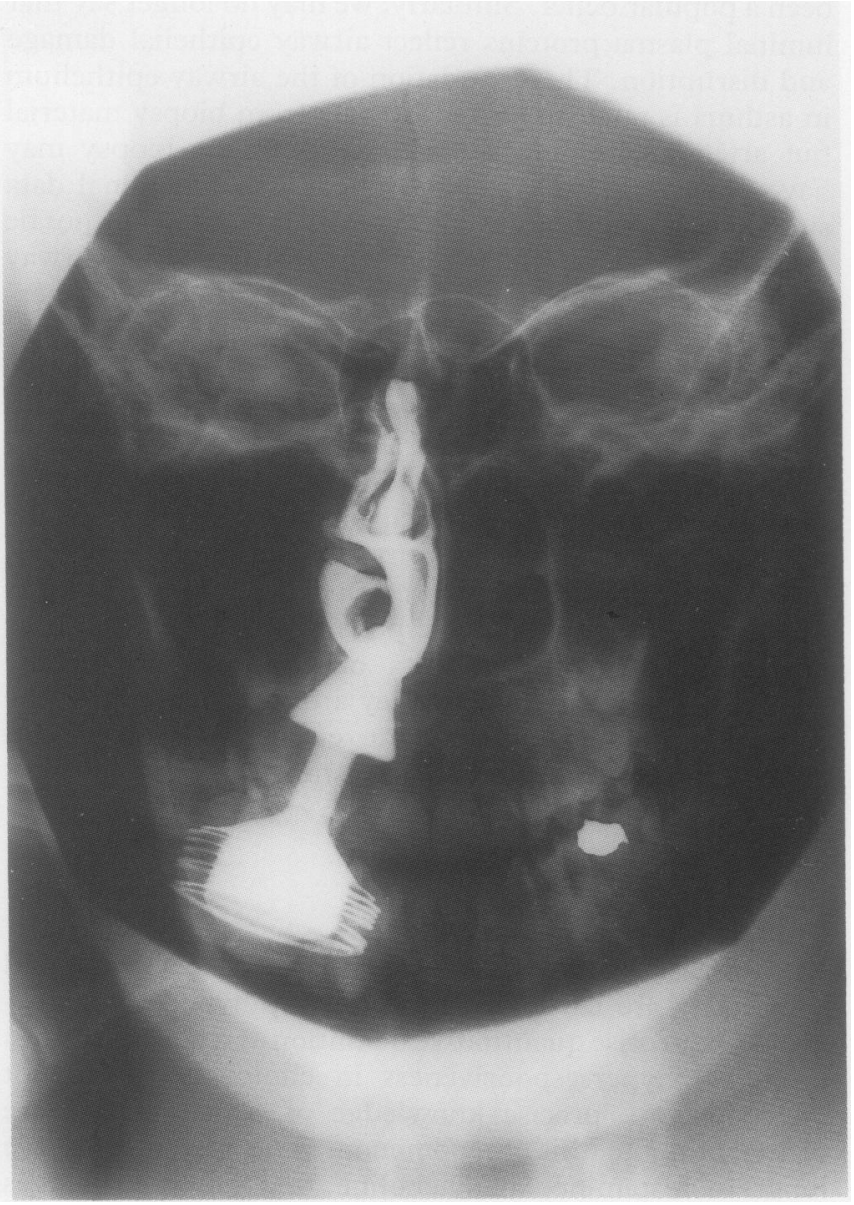

Figure 4 Unilateral nasal cavity filled with lavage fluid containing challenge agent, drug, tracer, or other solutes by means of a nasal pool device (see text).

\section{The nasal bath}

Research on airway inflammation requires different approaches for studies of mucosal cells and their traffic and activity. Nasal challenge and lavage studies are particularly useful. An example is the use of an "organ bath" in the nose. We have validated a nasal pool device (a compressible plastic container with a nasal orifice adapter) for use in research and clinical tests. One nasal cavity is gently filled with a solution containing saline, allergen, mediators, and drugs or tracers (or both).$^{96}$ If the device is compressed and the head flexed forward $60^{\circ}$ from the upright position, the defined pool solution can be kept in contact with a large and constant area of the surface of the nasal mucosa for a fixed time (fig 4). At the same time the pool of fluid gently lavages the mucosal surface. Exposure and lavage can be repeated as frequently as desired and the lavage itself has little or no effect on the airway mucosa. Furthermore, the lavage procedure is so easy that it can be carried out by the patient after minimal training. Indices of the solutes on the mucosal surface can therefore be conveniently sampled even at home and at work. Its non-traumatic nature and the fact that it does not call for any local anaesthetic or other form of premedication, the airway specificity, the quantitative recovery, the unlimited repeatability, and its safety distinguish nasal lavage ${ }^{96101}$ from bronchoalveolar lavage. ${ }^{79} 80$

\section{Conclusion}

The explosion of knowledge at the cellular and molecular levels has caused an escalation of need for in vivo studies where airway changes specific to inflammation can be assessed. In this editorial we have suggested that many similarities may exist between nasal, tracheal, and bronchial inflammation. Whether crucial differences exist and what they are will have to be addressed in future research. Several research groups in different parts of the world are now using the human nose in the search for the inflammatory mechanisms in airways diseases. This is reflected by a resurgence of interest in meetings and books where nasal and tracheobronchial inflammation are treated jointly. ${ }^{102-105}$ The human nose is a gratifying locale for safe and versatile investigations into the relation between cellular mechanisms and the mucosal functions and responses of the mucosal end organs. Nasal data should increase the understanding of allergic, occupational, and infectious airway diseases and improve the experimental approach in studies directed specifically at the human tracheobronchial mucosa. Solis-Cohen, Bullowa, and Kaplan advised the right treatment of asthma for the wrong "nasal" reason. At the end of this century research on the nasal mucosa is again aimed at doing the right thing both for nasal and for bronchial inflammation. The signs are that this will increasingly be for the right reason.

$$
\begin{array}{r}
\text { C G A PERSSON } \\
\text { Department of Clinical Pharmacology } \\
\text { C SVENSSON } \\
\text { L GREIFF } \\
\text { M ANDERSSON } \\
\text { Pepartment of Otorhinolaryngology } \\
\text { P WOLLMER } \\
\text { Department of Clinical Physiology } \\
\text { University Hospital of Lund, } \\
\text { S-221 85 Lund } \\
\text { U ALKNER } \\
\text { I ERJEFÄLT } \\
\text { Research and Development Department of Astra-Draco, } \\
\text { Lund, Sweden }
\end{array}
$$

This editorial is dedicated to the memory of our friend and colleague the late Ulf Pipkorn

This work was supported by the Swedish Medical Research Council projects 8308 and 2872; the Medical Faculty, University of Lund; Astra-Draco, Lund the Foundation of Torsten and Ragnar Söderberg; and the Swedish Association Against Asthma and Allergy. We thank Mai Broman for the secretarial work.

1 Åberg N. Asthma and allergic rhinitis in Swedish conscripts. Clin Exp Allergy 1989;19:59-63.

2 Persson CGA. Glucocorticoids for asthma-early contributions. Pulmon Pharmacol 1989;2:163-6.

3 Bosworth FM. An additional note on the therapeutic action of cocaine. N Y Med $J$ 1886;43:322-4.

4 Rackemann FM. Asthma and the nose and throat. New York: MacMillan, 1931:444-56.

5 Sluder G. Asthma as a nasal reflex. JAMA 1919;73:589-91.

6 Dixon WE, Brodie TG. The bronchial muscles, their innervation, and the actions of drugs upon them. J Physiol (Lond) 1903;23:97-173.

7 Sticker G. Der Bostock'sche Sommerkatarrh. Specielle Pathologie und Therapie 1896;4:87-142.

8 Persson CGA. On the medical history of asthma and rhinitis. In: Mygind N, Pipkorn U, Dahl R, eds. Rhinitis and asthma : similarities and differences. Copenhagen: Munksgaard, 1990:9-20.

9 Holmberg K, Bake B, Pipkorn U. The effect of topical anaesthesia on allergen-induced symptoms, obstruction and blood flow. Clin Exp Allergy 1989;19:443-7.

10 Greiff L, Erjefält I, Wollmer P, Andersson M, Pipkorn U, Alkner U, et al. Nicotine evokes neurogenic mucosal exudation of plasma into guinea pig but not into human airways. In: Greiff L, ed. Plasma exudation and solute absorption across the airway mucosa [thesis]. Lund: University of Lund, absorption across

11 Bascom R, Green S, Green D, Kagey-Sobotka A, Proud D. Effect of intranasal capsaicin on symptoms and mediator release [abstract]. $\mathrm{Am}$ Rev Respir Dis 1988;137:375.

12 Aubier M, Levy J, Clerici C, Neukirch F, Herman D. Different effects of nasal and bronchial glucocorticosteroid administration on bronchial hyperresponsiveness in patients with allergic rhinitis. Am Rev Respir Dis 1992;146:122-6.

13 Henriksen JM, Wenzel A. Effect of an intranasally administered corticosteroid (budesonide) on nasal obstruction, mouth breathing, and asthma. Am Rev Respir Dis 1984;130:1014-8.

14 Reed CE, Marcoux JP, Welsh PW. Effects of topical nasal treatment on asthma symptoms. J Allergy Clin Immunol 1988;81:1042-7.

15 Weber T. Zur Theorie des Bronchialasthma. Tagbl Vers dtsch Naturf Artzte 1872;45:159-71. 
16 Fraenkel A. Zur pathologischen Anatomie des Bronchialasthmas. Z Klin Med 1898;35:559-72.

17 Jezierski PV. Zur Pathologie des Asthma bronchiale. Dtsch Arch Klin Med 1906;85:342-7.

18 Widdicombe JG. Comparison between the vascular beds of upper and lower airways. Eur Respir J 1990;3(suppl 12):564-71S.

19 Solis-Cohen $\mathrm{S}$. The use of adrenal substance in the treatment of asthma. JAMA 1900;34:1164-6.

20 Bullowa JGM, Kaplan DM. On the hypodermatic use of adrenaline chloride in the treatment of asthmatic attacks. Medical News 1903;83: 787-90.

21 Erjefält I, Persson CGA. Long duration and high potency of anti-exudative effects of formoterol in guinea-pig tracheobronchial airways. Am Rev Respir Dis 1991;144:788-91.

22 Johnson $M$. The preclinical pharmacology of salmeterol: non-bronchial effects. Eur Respir Rev 1991;1;4:257-60.

23 Bordley JE, Carey RA, Harvey AM, Howard JE, Kattus AA, Newman EV, et al. Preliminar observations on the effect of adrenocorticotropic hormone (ACTH) in allergic disease. Bull Johns Hopkins Hosp 1949;85. 396-8.

24 Marchand F. Beitrag zur Pathologie und pathologischen Anatomie des Bronchialasthma. Betr Pathol Anat 1916;61:251-324.

25 Marchand F. Ein neuer Fall von Asthma bronchiale mit anatomischer Untersuchung:Dtsch Arch Klin Med 1918;127:184-209.

26 Kountz WB, Alexander HL. Death from bronchial asthma. Arch Pathol 1928;5:1003-19.

27 Klementsson H, Venge P, Andersson M, Pipkorn U. Allergen-induced changes in nasal secretory responsiveness and eosinophil granulocytes. Acta Otolaryngol (Stockh) 1991;111:776-84.

28 Klementsson $\mathrm{H}$, Andersson $\mathrm{M}$. Eosinophil chemotactic activity of topica PAF on the human nasal mucosa. Eur J Clin Pharmacol 1992;42:295-9.

29 Pipkorn U, Karlsson G, Enerbäck L. The cellular response of the human allergic mucosa to natural allergen exposure. J Allergy Clin Immunol 1988;82:1046-54.

30 Klementsson H, Svensson C, Andersson M, Venge P, Pipkorn U, Persson CGA. Eosinophils, secretory responsiveness and glucocorticoid-induced effects on the nasal mucosa during a weak pollen season. Clin Exp Allergy 1991;21:705-10.

31 Svensson C, Andersson M, Persson CGA, Venge P, Alkner U, Pipkorn U. Albumin, bradykinins and eosinophil cationic protein on the nasal mucosal surface in patients with hay fever during natural allergen exposure. J Allergy Clin Immunol 1990;85:828-33.

32 Venge $P$, Hảkansson $L$. The eosinophil and asthma. In: Kaliner MA, Barnes PJ, Persson CGA, eds. Asthma: its pathology and treatment. New York: Dekker, 1991:477-502.

33 Varney VA, Jacobson MR, Sudderick RM, Robinson DS, Irani AMM, Schwartz LB, et al. Immunohistology of the nasal mucosa following allergen-induced rhinitis. Am Rev Respir Dis 1992;146:170-6.

34 Vilsvik JS, Jensen AO, Walstad R. The effect of beclomethasone diproprionate aerosol on allergen induced nasal stenosis. Clin Allergy 1975;5:291-4.

35 Dahl R, Johansson S- $\AA$. Importance of duration of treatment with inhaled budesonide on the immediate and late bronchial reaction. In: Clark TJH Mygind N, Selroos O, eds. Corticosteroid treatment in allergic airway diseases. Eur J Respir Dis 1982;63(suppl 122):167-75.

36 Pipkorn U, Rundkrantz H, Lindqvist N. Budesonide-a new nasal steroid. Rhinology 1980;18:171-5.

37 Pipkorn U, Rundcrantz $\mathrm{H}$. Budesonide and beclomethasone diproprionate in hay fever-a single-blind comparison. Eur J Respir Dis 1982;63(suppl 122):211-20.

38 Pipkorn U, Proud D, Lichenstein LM, Kagey-Sobotka A, Norman PS, Naclerio RM. Inhibition of mediator release in allergic rhinitis by pretreatment with topical glucocorticosteroids. N Engl J Med 1987;316: 1506-10.

39 Enerbäck L. Mast cell heterogeneity: The evolution of the concept of a specific mucosal mast cell. In: Befus AD, Bienenstock J, Denburg JA, eds. Mast cell differentiation and heterogeneity. New York: Raven Press, 1986:1-26.

40 Pipkorn U, Enerbäck L. A method for the preparation of imprints from the nasal mucosa. J Immunol Methods 1984;73:133-7.

41 Enerbäck L, Pipkorn U, Graneus G. Intraepithelial migration of nasal mucosal mast cells in hay fever. Int Arch Allergy Appl Immunol 1986;80: 44-51.

42 Kaliner MA, Why do we have allergic reactions? Allergy Clin Immunol News 1992;4:67-8.

43 Andersson M, Nolte H, Baumgarten C, Pipkorn U. Suppressive effect of loratidine on allergen-induced histamine release in the nose. Allergy $1991 ; 46: 540-6$

44 Howarth PH. Histamine and asthma: an appraisal based on specific $\mathrm{H}_{1}$ receptor antagonism. Clin Exp Allergy 1990;20(suppl 2):31-41.

45 Castells M, Schwartz LB. Tryptase levels in nasal-lavage fluid as an indicator of the immediate allergic response. J Allergy Clin Immunol 1988;82:348-55.

46 Juliusson S, Holmberg K, Baumgarten CR, Olsson M, Enander I, Pipkorn $U$. Tryptase in nasal lavage fluid after local allergen challenge. Relationship to histamine levels and TAME-esterase activity. Allergy 1991;46: 459-65.

47 Salomonsson P, Grönnenberg R, Giljam H, Andersson O, Billing B, Enander I, et al. Bronchial exudation of bulk plasma at allergen challenge in allergic asthma. Am Rev Respir Dis (in press).

48 Gordon JR, Burd PR, Galli SJ. Mast cells as a source of multifunctional cytokines. Immunol Today 1990;11:458-64.

49 Gauldie J, Jordana M, Cox G, Ohtoshi T, Dolovich J, Denburg J Fibroblasts and other structural cells in airway inflammation. Am Rev Respir Dis 1992;145(suppl 2):S14-7.

50 Cox G, Ohtoshi T, Vancheri C, Denburg JA, Dolovich J, Gauldie J, et al. Promotion of eosinophil survival by human bronchial epithelial cells and its modulation by steroids. Am J Respir Cell Mol Biol 1991;4:525-31.
51 Marinin M, Soloperto M, Mezzetti M, Fasoli A, Mattoli S. Interleukin-1 binds to specific receptors on human bronchial epithelial cells and upregulates granulocyte/macrophage colony-stimulating factor synthesis and release. Am J Respir Cell Mol Biol 1991;4:519-24.

52 Hectman DH, Cybulsky MI, Fuchs HJ, Baker JB, Gimbrone MA. Intravascular IL-8: inhibitor of polymorphonuclear leukocyte accumulation at sites of acute inflammation. $J$ Immunol 1991;147:883-92.

53 Trinchieri G, Perussia B. Immune interferone: a pleiotropic lymphokine with multiple effects. Immunol Today 1985;6:131-6.

54 Linden M, Åkerlung A, Andersson M, Greiff L, Bende M, Svensson C, et al. Coronavirus $299 \mathrm{E}$ infection increases human airway secretion of interferon-gamma in vivo [abstract]. Eur Respir J 1992;5(suppl 15):52-3S.

55 Crouch E. Pathobiology of pulmonary fibrosis. Am J Physiol 1990;259: L159-84.

56 Montefort S, Feather IH, Wilson SJ, Haskard DO, Lee TH, Holgate ST, et al. The expression of leukocyte endothelial adhesion molecules is increased in perennial allergic rhinitis [abstract]. Thorax 1992;47:232P.

57 Ando N, Fukuda T, Nakajima H, Makino S. Expression of intercellular adhesion molecule-1 (ICAM-1) is upregulated in the bronchial mucosa of symptomatic asthmatics [abstract]. J Allergy Clin Immunol 1992;89:215.

58 Ying S, Robinsin DS, Varney V, Qiu Meng, Tsicopoulos A, Moqbel R, et al. TNF-alpha mRNA expression in allergic inflammation. Clin Exp Allergy 1991;21:745-50.

59 Fokkens WJ. The pathogenesis of allergic rhinitis: cellular aspects with special emphasis on Langerhans cells [thesis]. Rotterdam: Erasmus University, 1991.

60 Holt PG, McMenamin C, Schon-Hegrad MA, Strickland D, Nelson D, Wilkes $\mathrm{L}$, et al. Immunoregulation of asthma: control of T-lymphocyte activation in the respiratory tract. Eur Respir J 1991;4(suppl 13):6-15S.

61 Vachier I, Godard P, Michel FB, Descomps B, Damon M. Expression aberrante des antigenes HLA-DR du CMH classe II dans les cellules épithéliales bronchiques de l'asthmatique. CR Acad Sci (Paris) 1990; 311(série III):341-6.

62 Poulter LW, Norris A, Power C, Condez A, Burnes H, Schmekel B, et al. Tcell dominated inflammatory reactions in the bronchioles of asymptomatic asthmatics are also present in the nasal mucosa. Postgrad Med J 1991; 67:747-53.

63 Garofalo R, Kimpen JLL, Welliver RC, Ogra PL. Eosinophil degranulation in the respiratory tract during naturally acquired respiratory syncytial virus infection. J Pediatr 1992;120:28-32.

64 Gandevia B. Respiratory symptoms and ventilatory capacity in men exposed to isocyanate vapor. Australasian Ann Med 1964;13:157-66.

65 Persson CGA. Ipecacuanha asthma-more lessons [letter]. Thorax 1991; 46:467-8.

66 Persson CGA. Plasma exudation in the airways: mechanisms and function. Eur Respir J 1991;4:1268-74.

67 Erjefailt I, Persson CGA. Inflammatory passage of plasma macromolecules into airway wall and lumen. Pulm Pharmacol 1989;2:93-102.

68 Alkner U, Svensson C, Andersson M, Pipkorn U, Persson CGA. Fibrinogen and albumin on the surface of allergen- and histamine-exposed human nasal mucosa [abstract]. J Allergy Clin Immunol 1991;87:217.

69 Grega GJ, Persson CGA, Svensjö E. Endothelial cell reactions to inflammatory mediators assessed in vivo by fluid and solute flux analysis. In: Ryan US, ed. Endothelial cells. Boca Raton, Florida: CRC Press, 1988: 103-19.

70 Persson CGA. Plasma exudation and asthma. Lung 1988;166:1-23.

71 Persson CGA, Erjefält I, Alkner U, Baumgarten C, Greiff L, Gustafsson B, et al. Plasma exudation as a first line respiratory mucosal defence. Clin Exp Allergy 1991;21:17-24.

72 Svensson C, Klementsson H, Alkner U, Pipkorn U, Persson CGA. A topical glucocorticoid reduces the levels of fibrinogen and bradykinins on the allergic nasal mucosa during natural pollen exposure [abstract]. $J$ Allergy Clin Immunol 1991;87:147.

73 Van de Graaf EA, Out TA, Roos CM, Jansen HM. Respiratory membrane permeability and bronchial hyperreactivity in patients with stable asthma. Effects of therapy with inhaled steroids. Am Rev Respir Dis 1991;143:362-8.

74 Bende M, Lindqvist N, Pipkorn U. Effect of a topical glucocorticoid, budesonide, on nasal mucosal blood flow as measured with ${ }^{133} \mathrm{Xe}$ wash-out technique. Allergy 1983;38:461-4

75 Svensson C, Greiff L, Andersson M, Alkner U, Persson CGA. Topical steroids may not inhibit vascular permeability in human airways [abstract]. Allergy 1992;47(suppl 12):6.

76 Svensson C, Pipkorn U, Alkner U, Baumgarten CR, Persson CGA. Topical vasoconstrictor (oxymetazoline) does not affect histamine-induced mucosal exudation of plasma in human nasal airways. Clin Exp Allergy 1992;22:411-6.

77 Cohnheim J. Vorlesung über allgemeine Pathologie. Vol 1. Berlin: Hirschwald, 1882:232-367.

78 Malik AB, Staub NC, eds. Mechanisms of lung microvascular injury. Ann N Y Acad Sci 1982;384:1-562.

79 Walters EH, Gardiner PV. Bronchoalveolar lavage as a research tool. Thorax 1991;46:613-8.

80 Venge $P$, Brattsand R, Laitinen LA, Persson CGA. Which markers of inflammation should be used in therapeutic intervention studies of CB/COAD? In: Persson CGA, Brattsand R, Laitinen LA, Venge P, eds. Inflammatory indices in chronic bronchitis. Agents Actions 1990;30 (suppl):289-94.

81 Svensson C, Baumgarten CR, Pipkorn U, Alkner U, Persson CGA. Reversibility and reproducibility of histamine induced plasma leakage in nasal airways. Thorax 1989;44:13-8.

82 Erjefalt I, Persson CGA. Allergen, bradykinin, and capsaicin increase outward but not inward macromolecular permeability of guinea-pig tracheobronchial mucosa. Clin Exp Allergy 1991;21:217-24

83 Grieff L, Wollmer P, Pipkorn U, Persson CGA. Absorption of ${ }^{51} \mathrm{Cr}$ EDTA across the human nasal airway barriers in the presence of topical histamine. Thorax 1991;46:630-2.

84 Greiff L, Erjefält I, Wollmer P, Pipkorn U, Persson CGA. Effects of 
histamine, ethanol, and a detergent on exudation and absorption across guinea pig airway mucosa in vivo. Thorax 1991;46:700-5.

85 Erjefält I. Plasma exudation in tracheobronchial airways: physiological and pharmacological study in the guinea-pig [thesis]. Lund: University of Lund, 1991.

86 Persson CGA, Erjefalt I, Gustafsson B, Luts A. Subepithelial hydrostatic pressure may regulate plasma exudation across the mucosa. Int Arch Allergy Appl Immunol 1990;92:148-53.

87 Gustaffsson BG, Persson CGA. Asymmetrical effects of increases in hydrostatic pressure on macromolecular movement across the airway mucosa. A study in guinea-pig tracheal tube preparations. Clin Exp Allergy 1991;21:121-6.

88 Persson CGA. Role of plasma exudation in asthma. Lancet 1986;ii:1126-9.

89 Söderberg M, Hellström S, Sandström T, Lundgren R, Bergh A. Structural characterization of bronchial mucosal biospies from healthy volunteers: a light and electron microscopical study. Eur Respir J 1990; 3:261-6.

90 Laitinen LA, Laitinen A, Persson CGA. Role of epithelium. In: Weiss EB, Segal MS, eds. Bronchial asthma. Boston: Little, Brown, 1990:296-308.

91 Lozewics S, Wells C, Gomez E, Ferguson H, Richman P, Devalia J, Davies RJ. Morphological integrity of the bronchial epithelium in mild asthma. Thorax 1990;45:12-5.

92 Greiff I Wollmer P, Svensson C, Andersson M, Persson CGA. Reduced mucosal absorption ability in allergic rhinitis [abstract]. Allergy 1992; 47(suppl 12):246.

93 Elwood RK, Kennedy S, Belzberg A, Hogg JC, Paré PD. Respiratory mucosal permeability in asthma. Am Rev Respir Dis 1983;128:523-7.

94 Hargreave FE, Woolcock AJ, eds. Airway responsiveness: measurement and interpretation. Ontario: Astra Pharmaceuticals Canada, 1985:1-146.
95 Kaliner MA, Barnes PJ, Persson CGA, eds. Asthma: its pathology and treatment. New York: Dekker, 1991.

96 Greiff L, Pipkorn U, Alkner U, Persson CGA. The nasal pool-device applies controlled concentrations of solutes on human nasal airway mucosa and samples its surface exudations/secretions. Clin Exp Allergy 1990;20: 253-9.

97 Rapheal GD, Druce HM, Baraniuk JN, Kaliner MA. Pathophysiology of rhinitis. 1. Assessment of the sources of protein in methacholine-induced nasal secretions. Am Rev Respir Dis 1988;138:413-20.

98 Stjärne P, Lundblad L, Lundberg JM, Änggård A. Capsaicin and nicotinesensitive afferent neurones and nasal secretions in healthy human vol teers and in rmacol 1989 96:693-701.

99 Forsberg K, Karlsson J-A, Zakrisson C, Persson CGA. Selective inhibition of cough and bronchoconstriction in conscious guinea-pigs. Respiration 1992;59:72-6.

100 Midgren B, Hansson L, Karlsson J-A, Simonsson BG, Persson CGA Capsaicin-induced cough in man. Am Rev Respir Dis 1992;146:347-51.

101 Naclerio RM, Meier HL, Kagey§Sobotka A, Adkinson Jr NF, Meyers DA, Norman PS, et al. Mediator release after nasal airway challenge with allergen. Am Rev Respir Dis 1983;128:597-602.

102 Mygînd N, Pipkorn U, Dahl R, eds. Rhinitis and asthma: similarities and differences. Copehhagen: Munksgaard, 1990.

103 Laitinen LA, Salonen RO, Widdicombe JG, eds. Trachreobronchial and nasal circulation. Eur Respir J 1990;3(suppl 12):553-684S

104 Holgate ST, Busse WW, eds. Asthma and rhinitis. London: Blackwell (in press).

105 Bousquet J, ed. Airway inflammation: the basis of rhinitis and asthma. Research and (linical Forums 1992;14:1-93. 